Research Article

\title{
Preparation and Characterization of Methotrexate Loaded Polymeric Nanoparticles by Nanoprecipitation Technique
}

\author{
Ayesha Siddiqua Gazi, Abbaraju Krishnasailaja \\ RBVRR Women’s College of Pharmacy, Osmania University, Barkatpura, Hyderabad, India. \\ Corresponding author. E-mail: asharpai2013@gmail.com
}

Received: Sep.Apr. 8, 2019; Accepted: Nov. 18, 2019; Published: Nov. 18, 2019.

Citation: Ayesha Siddiqua Gazi, Abbaraju Krishnasailaja, Preparation and Characterization of Methotrexate Loaded Polymeric Nanoparticles by Nanoprecipitation Technique. Nano Biomed. Eng., 2019, I I (4): 35I-360.

DOI: 10.5101/nbe.v11i4.p351-360.

\begin{abstract}
The aim of this study was to develop and characterize methotrexate-loaded polymeric nanoparticles by nanoprecipitation technique. Eudragit ${ }^{\circledR}$ S 100 and ethyl cellulose were employed to develop methotrexate-loaded nanoparticles by nanoprecipitation technique. Six different formulations (f1, f2, f3, f4, f5 and f6) were prepared with each polymer by varying the drug to polymer ratios (1:1, 1:1.5, 1:2, 1:3, 1.5:1 and 2:1). Dimethyl sulfoxide (DMSO) was used as a solvent and Tween ${ }^{\circledR} 20$ as a surfactant. Among the six formulations of polymeric nanoparticles prepared by nanoprecipitation technique, F4 formulation was considered as a best formulation with each polymer. Based on comparison results of mean particle diameter, zeta potential, drug content and entrapment efficiency, Eudragit ${ }^{\circledR}$ S 100 was considered to be the most suitable polymer for preparation of methotrexate-loaded nanoparticles by nanoprecipitation technique. Based upon the evaluation studies, the best formulation was characterized for scanning electron microscopy (SEM), particle size, zeta potential and anti-cancer activity in MCF-7 cell line by MTT assay.
\end{abstract}

Keywords: Methotrexate; Polymeric nanoparticles; Nanoprecipitation technique

\section{Introduction}

A conventional preparation like solutions, suspensions or emulsions for drug delivery has certain restrictions like high dose and low bioavailability, intolerance, instability. They show some changes in the blood plasma drug levels and do not provide sustained effect. Due to the attendance of acidic and basic medium in the body, it is essential that every drug should reach the target site without any alteration in its physical and chemical properties [1, 2]. The major focus on Novel drug delivery systems during the past two decades is to improve the therapeutic efficacy and safety profile of the drug substances. Among all the colloidal systems, nanoparticles hold promise as drug delivery through various routes due to their greater stability and easier manufacturing ability. And also since many years, there has been a shift in drug delivery research from micro to nanoscale. Thus, nanotechnology is evolving as a promising field in medicine that shows significant therapeutic benefits. These systems are used for specific drug delivery, controlled drug delivery and also for the improvement of bioavailability of the hydrophobic drugs [3, 4].

Methotrexate (MTX), a dihydrofolate reductase inhibitor, is one of the most widely used drugs for the 
treatment of various neoplastic diseases. It is used in the treatment of certain cancers like breast cancer, skin and lung cancer. Clinical studies have revealed that the curative effect of MTX tablet regarding cancers was limited due to its toxic dose-related side effects to normal cells, nephrotoxicity, immunosuppressant, bone marrow suppression, and ulcerative stomatitis, acute and chronic hepatotoxicity and also due to the drug resistance of the tumor cells. Hence, there is a need to develop methotrexate nanoparticles in order to minimize the adverse effects associated with the MTX tablet dosage form $[5,6]$.

Nanoprecipitation is also called solvent displacement or interfacial deposition. It is considered as one of the first developed techniques used for the encapsulation of drug molecules [7]. This technique was developed by Fessi et al. (1989). Although, several techniques have been used for the preparation of submicron particles from preformed polymers, nanoprecipitation is regarded as a quite simple and reproducible technique that allows the obtaining of submicron-sized polymer particles $[8,9]$.

In the present study, attempts have been made to prepare methotrexate nanoparticles by using Eudragit ${ }^{\circledR}$ S 100 and ethyl cellulose (EC) as a polymer as these are low cost polymer and can formulate the methotrexate nanoparticles in academic research.

\section{Experimental}

\section{Materials}

Drug: Methotrexate, gift sample from Mac-Chem Products (India) Pvt. Ltd., Mumbai.

Polymers: Eudragit@ S 100, ethyl cellulose obtained from SD Fine Chem. Limited, Mumbai.

Solvent: DMSO, acetone obtained from SD Fine Chem. Limited, Mumbai.

Stabilizer: Tween ${ }^{\circledR} 20$ obtained from SD Fine Chem. Limited, Mumbai.

\section{Methods}

Methotrexate loaded polymeric nanoparticles were prepared by nanoprecipitation technique. Eudragit ${ }^{\circledR} \mathrm{S}$ 100 and ethyl cellulose was selected as a polymer for this technique. DMSO was used as a solvent [10].

\section{Nanoprecipitation}

Six different formulations (F1, F2, F3, F4, F5, and
F6) were prepared by varying the drug to polymer ratio. Weighed quantities of Methotrexate and Eudragit ${ }^{\circledR}$ S100 / ethyl cellulose were dissolved in $10 \mathrm{~mL}$ of dimethyl sulphoxide. (Ethyl cellulose was dissolved in acetone before adding DMSO). The organic phase was then added to $25 \mathrm{~mL}$ of aqueous phase containing $0.1 \%$ Tween ${ }^{\circledR} 20$ surfactant with continuous stirring at $500 \mathrm{rpm}$. The appearance of precipitate was considered as the end point. After the attainment of endpoint, the solution was kept for stirring for 5 hours. The formed precipitate was separated from the solution by means of vacuum rotary evaporator. The obtained precipitate was air-dried to completely remove the moisture content [11, 12].

Table 1 Formulation ratios of methotrexate loaded ES 100 / ethyl cellulose nanoparticles

\begin{tabular}{ccc}
\hline Formulation & Ratio of drug to polymer used & Optimized parameters \\
\hline F1 & $1: 1$ & \\
F2 & $1: 1.5$ & DMSO \\
F3 & $1: 2$ & $0.1 \%$ v/v Tween \\
F 20 \\
F4 & $1: 3$ & $500 \mathrm{rpm}$ \\
F5 & $1.5: 1$ & $5 \mathrm{~h}$ \\
F6 & $2: 1$ & \\
\hline
\end{tabular}

\section{Evaluation studies [13]}

The obtained formulations of technique are evaluated for the following parameters.

\section{Determination of drug content}

Free drug of the formulations was first determined in the supernatant by choosing a solvent in which only the free drug got dissolved and not the other ingredients. To determine the drug content, $50 \mathrm{mg}$ drug equivalent to formulation was weighed accurately and transferred into $100 \mathrm{~mL}$ beaker containing $50 \mathrm{~mL}$ of DMSO. The solution was stirred at $700 \mathrm{rpm}$ for 3 h by using magnetic stirrer. The resultant solution was filtered and the amount of the drug in the filtrate was estimated after suitable dilution by UV spectrophotometer at $303 \mathrm{~nm}[14,15]$.

\section{Entrapment efficiency [16]}

Entrapment efficiency indicates the amount of drug encapsulated in the formulation. The method of choice for entrapment efficiency determination is separation of free drug by ultracentrifugation, followed by quantitative analysis of the drug from the formulation. The samples were centrifuged by using ultracentrifuge at $17000 \mathrm{rpm}$ for $40 \mathrm{~min}$. 
Percentage entrapment efficiency may be calculated from the following formula:

Entrapment efficiency $=($ Amount of drug encapsulated in the formulation / Total amount of drug in the formulation) $\times 100$.

\section{Loading capacity [17]}

It indicates the capacity of the polymer to load a drug.

Loading capacity $=[$ (Total amount of drug - Amount of free drug concentration) / Nanoparticles weight] $\times$ 100.

\section{In-vitro drug release kinetics $[18,19]$}

In-vitro drug release studies were conducted by means of orbitary shaker. $50 \mathrm{mg}$ of each accurately weighed formulation was transferred into $250 \mathrm{~mL}$ conical flask containing $50 \mathrm{~mL}$ pH 7.4 phosphate buffer. They were kept in an orbitary shaker at 100 rpm maintained at $37^{\circ} \mathrm{C}$. Aliquots of $2 \mathrm{~mL}$ buffer were withdrawn at predefined time intervals and the medium was replaced with same volume of buffer. This study was carried out for $12 \mathrm{~h}$, and the amount of drug release was estimated by determining the absorbance at $303 \mathrm{~nm}$ using Elico UV spectrophotometer.

\section{Characterization of nanoparticles [20] Particle size analysis and zeta potential measurement $[21,22]$}

The average particle size and size distribution of MTX polymeric nanoparticles were determined by dynamic light scattering (DLS), using Malvern Zetasizer. The zeta potential (surface charge) which indicates the stability of the nanoparticle's can be defined as electrokinetic potential that is determined by electrophoretic mobility. Samples were prepared by diluting with water and corresponding zeta potential was measured using Malvern Zeta Sizer.

\section{Determining the size and morphology of the nanoparticles [23, 24]}

Scanning electron microscopy (SEM) was used to determine the shape, size and surface morphology of the MTX polymeric nanoparticles. Nanoparticulate suspension is made to obtain photomicrographs using SEM.

\section{In vitro cytotoxicity assay Aim}

To determine the Anti-cancer activity of test compounds in vitro by MTT Assay.

\section{Materials and methods}

Dulbecco's modified Eagles medium (DMEM), MTT [3-(4,5-dimethylthiazol-2-yl)-2,5-diphenyl tetrazolium bromide], trypsin, and EDTA phosphate buffered saline (PBS) were purchased from Sigma Chemicals Co. (St. Louis, MO). Fetal bovine serum (FBS) was purchased from Gibco, $25 \mathrm{~cm}^{2}$ and $75 \mathrm{~cm}^{2}$ flask and 96 well plated purchased from Eppendorf India [25, 26].

\section{Procedure}

Cell viability was evaluated by the MTT Assay with three independent experiments with six concentrations of compounds in triplicates. Cells were trypsinized and perform the tryphan blue assay to know viable cells in cell suspension. Cells were counted by haemocytometer and seeded at density of $5.0 \times 10^{3}$ cells / well in $100 \mu \mathrm{L}$ media in 96 well plate culture medium and incubated overnight at $37^{\circ} \mathrm{C}$. After incubation, take off the old media and add fresh media $100 \mu \mathrm{L}$ with different concentrations of test compound in the wells in 96 plates. After 48 h., Discard the drug solution and add the fresh medic with MTT solution $(0.5 \mathrm{mg} / \mathrm{mL})$ was added to each well and plates were incubated at $37^{\circ} \mathrm{C}$ for $3 \mathrm{~h}$. At the end of incubation time, precipitates are formed as a result of the reduction of the MTT salt to chromophore formazan crystals by the cells with metabolically active mitochondria. The optical density of solubilized crystals in DMSO was measured at 570 $\mathrm{nm}$ on a microplate reader. The percentage growth inhibition was calculated using the following formula and concentration of test drug needed to inhibit cell growth by $50 \%$ values is generated from the doseresponse curves for each cells using with origin software [27, 28].

Inhibiiton $(\%)=[($ Control - Treatment $) /$ Control $] \times$ 100

\section{Results and Discussion}

The obtained formulations were evaluated for the above mentioned parameters and the results are discussed as follows.

\section{Evaluation results of methotrexate- Eudragit ${ }^{\circledR}$ S 100 nanoparticles Drug content}

All the prepared formulations of MTX loaded 
Eudragit ${ }^{\circledR}$ S100 nanoparticles were evaluated for drug content.

Drug content of the formulations, F1-F6 was found to be $72 \pm 2 \%, 72.6 \pm 3 \%, 80.4 \pm 2 \%, 93.1 \pm 3 \%, 77.2 \pm 2 \%$, and $62.6 \pm 2 \%$, respectively. These results revealed that all the formulations showed good drug content and F4 formulation showed the highest percentage of drug content, i.e.; $93.1 \pm 3 \%$.

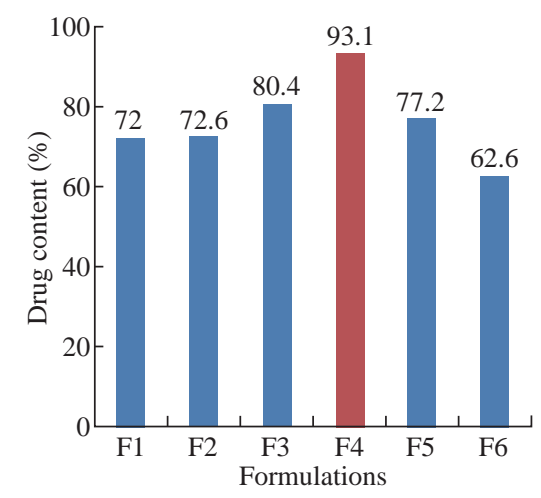

Fig. 1 Drug content of methotrexate-Eudragit ${ }^{\circledR}$ S100 nanoparticles.

\section{Entrapment efficiency}

The entrapment efficiency of all the formulations, i.e. F1-F6, was determined to be $77.09 \pm 2 \%$, $79.19 \pm 3 \%, 80.06 \pm 2 \%, 82.5 \pm 3 \%, 72.75 \pm 1 \%$ and $74.9 \pm 2 \%$, respectively. As the amount of polymer was increased from F1 to F4 formulation, the encapsulation efficiency was increased. However, on increasing the drug concentration, there was decrease in entrapment efficiency that could be due to an inadequate amount of polymer present in the system being insufficient to entrap the drug inside the matrix.

Thus, the optimum drug encapsulation was found to be for F4 formulation showing i.e.; 82.5\%.

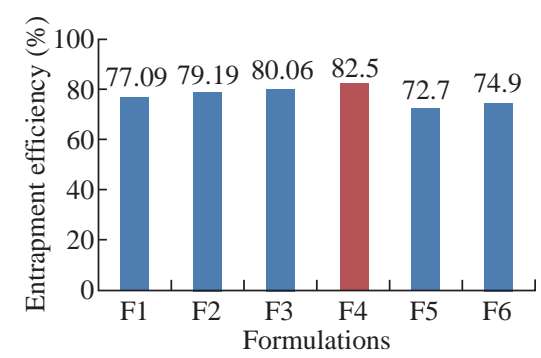

Fig. 2 Drug entrapment efficiency of methotrexate-Eudragit ${ }^{\circledR}$ S100 nanoparticles.

\section{Loading capacity}

Loading capacity of all the formulations, F1-F6 was found to be $26.9 \%, 27.4 \pm 1 \%, 25.04 \pm 2 \%, 16.6 \pm 1 \%$, $33.3 \pm 2 \%$ and $29.58 \pm 2 \%$, respectively. By comparison, F5 formulation showed higher loading capacity than other formulations.

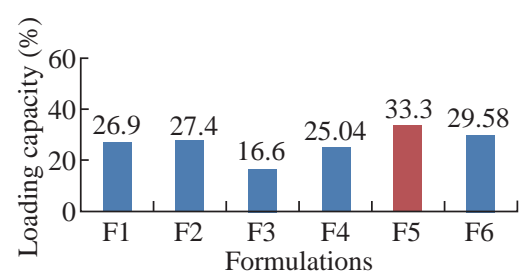

Fig. 3 Loading capacity of Methotrexate-Eudragit ${ }^{\circledR}$ S100 nanoparticles.

\section{In-vitro drug release studies}

The in-vitro drug release studies were performed for all the formulations of MTX loaded ES 100 nanoparticles in $7.4 \mathrm{pH}$ phosphate buffer conducted by means of orbitary shaker (Orchid, Scientifics) for a time period of $12 \mathrm{~h}$.

Among all the formulations, the drug release from F4 formulation was good and the release was sustained up to 12 h, i.e.; $89.8 \pm 3 \%$ in 12 h.

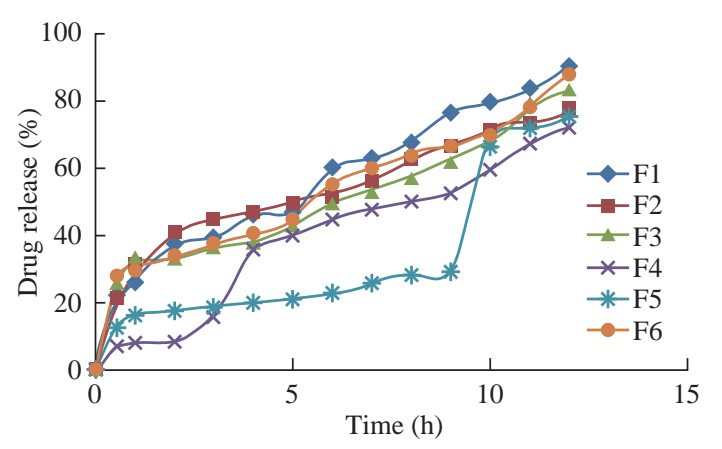

Fig. 4 In-vitro drug release profile of methotrexate-Eudragit $\left({ }^{\circledR}\right.$ S100 nanoparticles.

\section{Evaluation results of methotrexate-ethyl cellulose nanoparticles Drug content}

Drug content of the formulations F1-F6 was found to be $68.9 \pm 2 \%, 69.02 \pm 2 \%, 70.6 \pm 3 \%, 75 \pm 3 \%, 70.2 \pm 2 \%$ and $82.3 \pm 2 \%$, respectively. These results revealed that all the formulations showed good drug content and F6 formulation showed the highest percentage of drug content, i.e.; $82.3 \pm 2 \%$.

\section{Entrapment efficiency}

Entrapment efficiency of all the formulations, F1-F6 was determined to be $61.4 \pm 2 \%, 65.9 \pm 2 \%, 74.2 \pm 3 \%$, $79.3 \pm 2 \%, 59.5 \pm 2 \%$ and $53.4 \pm 3 \%$, respectively. 


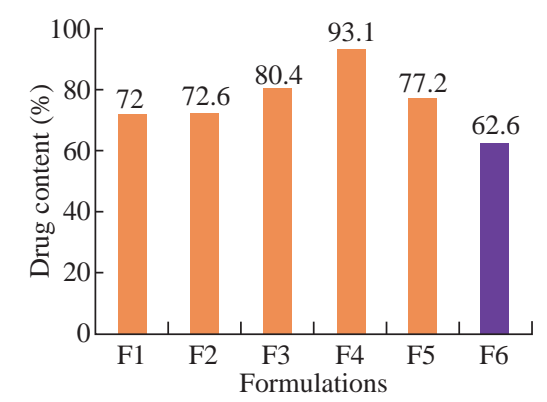

Fig. 5 Drug content of methotrexate-ethyl cellulose nanoparticles.

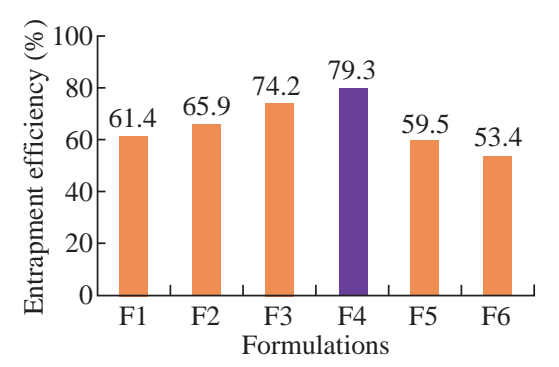

Fig. 6 Drug entrapment efficiency of methotrexate-ethyl cellulose nanoparticles.

\section{Loading capacity}

Loading capacity of all the formulations, F1-F6 was found to be $21.54 \pm 2 \%, 20.57 \pm 2 \%, 19.25 \pm 3 \%$, $18.1 \pm 2 \%, 24.6 \pm 2 \%$ and $29.7 \pm 2 \%$, respectively. By comparison, F6 formulation showed higher loading capacity than the other formulations.

\section{In-vitro drug release studies}

Among all formulations F4 (1:3) formulation showed maximum drug release of $90.05 \pm 2 \%$ in a time period of $12 \mathrm{~h}$ as shown in Fig. 8.

\section{Average particle size}

Size distributions of the prepared nanoparticles along the mean diameter was measured using particle size analyser. Average particle size of the prepared drug loaded Eudragit ${ }^{\circledR}$ S100 nanoparticles was recorded. The minimum value was found for F4 formulation as of $704.3 \mathrm{~nm}$ (Fig. 9).

\section{Zeta potential}

Zeta potential of the prepared drug loaded Eudragit ${ }^{\circledR}$ S100 nanoparticles was measured using zeta sizer. Nanoparticles of F4 formulation showed higher stability, bearing a value of $-21.3 \mathrm{mV}$.

\section{Average particle size and zeta potential}

The size distributions of the prepared nanoparticles along the mean diameter were measured using particle

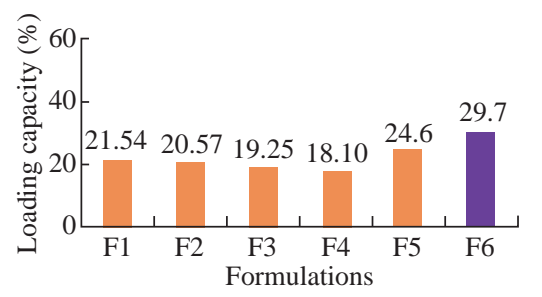

Fig. 7 Loading capacity of methotrexate-ethyl cellulose nanoparticles.

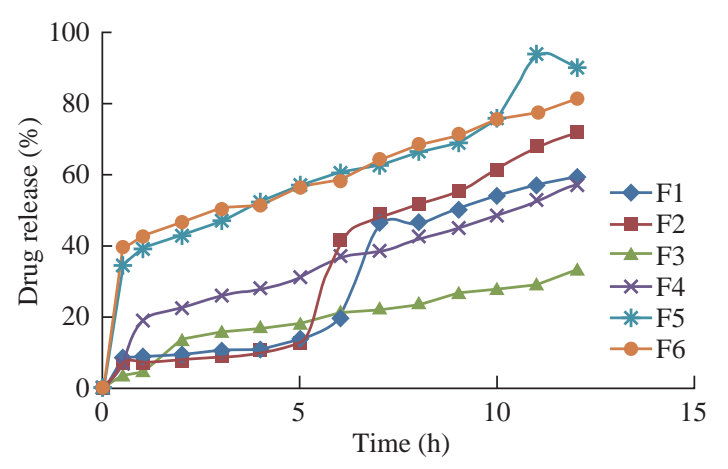

Fig. 8 In-vitro drug release profile of methotrexate-ethyl cellulose nanoparticles.

size analyser. The average particle size of the prepared drug loaded ethyl cellulose nanoparticles was recorded. The minimum value was found for F4 formulation as of $622.6 \mathrm{~nm}$ (Fig. 11 and 12).

\section{Zeta potential}

Zeta potential of the prepared drug loaded ethyl cellulose nanoparticles was measured using zeta sizer. Nanoparticles of F4 formulation showed higher stability, bearing a value of $-23.3 \mathrm{mV}$.

\section{In-vitro cytotoxicity assay}

Based on the characterization and evaluation studies of the best formulations prepared by nanoprecipitation technique, MTX-EC (1:3) was considered as a best formulation and determine for the anticancer activity on MCF-7 cell line by MTT assay.

Cisplatin was taken as a standard and its $\mathrm{IC}_{50}$ value was observed to be $4.7 \mu \mathrm{M}$.

The $\mathrm{IC}_{50}$ value for the given formulation (MTX-EC 1:3) was found to be $74.65 \mu \mathrm{g}$.

\section{Discussion}

In the present study, attempts have been made to prepare methotrexate nanoparticles by using Eudragit ${ }^{\circledR}$ S100 and ethyl cellulose as a polymer as these are low cost polymer and can formulate the methotrexate nanoparticles in academic research. Methotrexate acts 


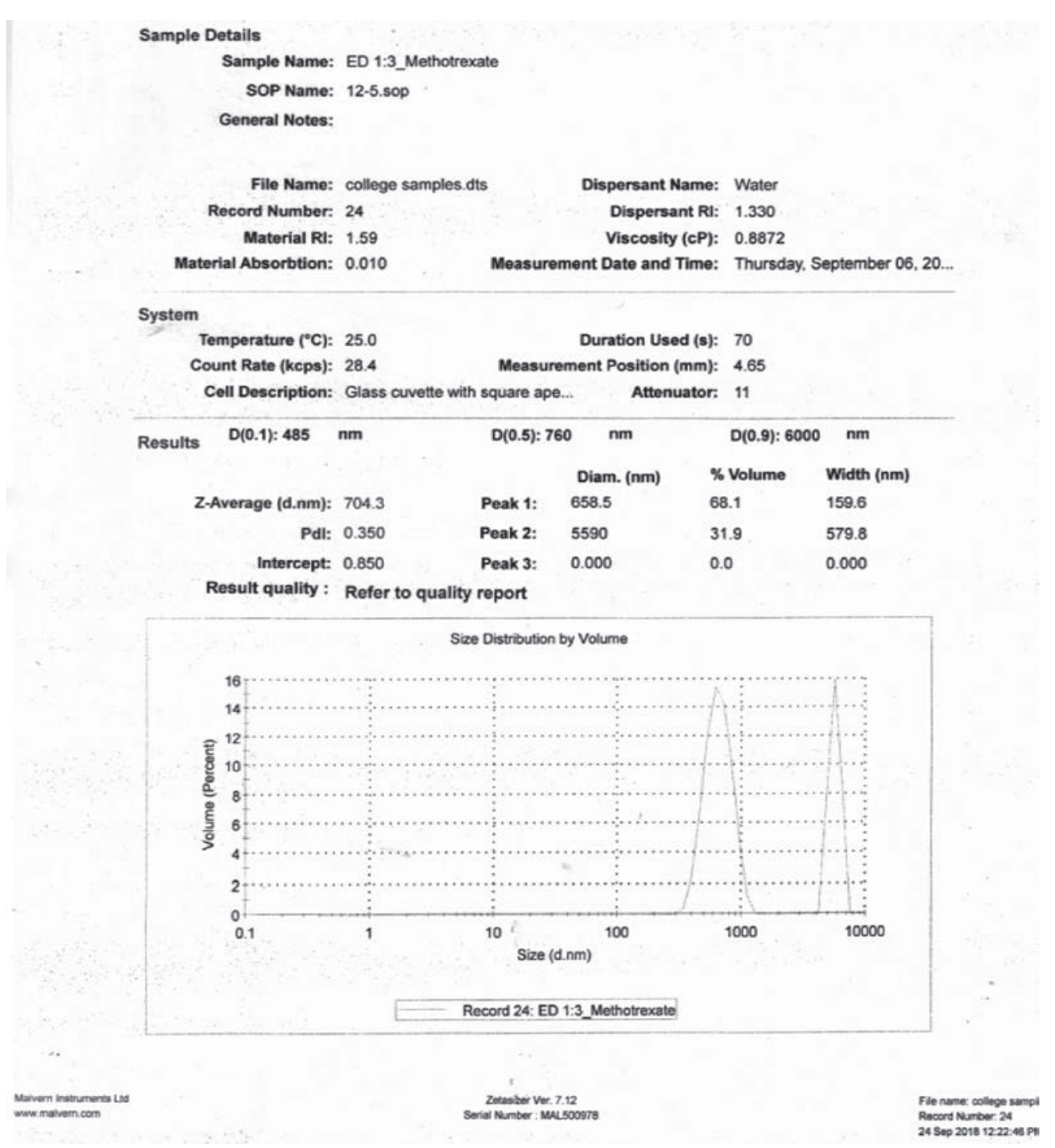

Fig. 9 Particle size analysis of F4 formulation.

Table 2 Cytotoxicity effect of F4 formulation (methotrexateethyl cellulose 1:3) on the growth of MCF-7 cell line

\begin{tabular}{cccc}
\hline Concentration $(\mu \mathrm{g})$ & OD at 570 & Inhibition (\%) & Viability (\%) \\
\hline 5 & 0.281 & 20.62 & 79.38 \\
10 & 0.175 & 50.56 & 49.44 \\
25 & 0.177 & 50 & 50 \\
50 & 0.167 & 52.82 & 47.18 \\
75 & 0.163 & 53.95 & 46.05 \\
100 & 0.192 & 45.76 & 54.24 \\
\hline
\end{tabular}

as anti-cancer drug through its anti-metabolic effect by interfering with DNA and RNA growth by substituting for the normal building blocks of RNA and DNA. MTX is one of the most commonly used chemotherapeutic agent for human malignancies. Six formulations (1:1,
Table 3 IC $_{50}$ value of methotrexate-EC 1:3 formulation

\begin{tabular}{ccc}
\hline \multirow{2}{*}{ S. No. } & Sample name & IC50 $(\mu \mathrm{g})$ \\
\cline { 3 - 3 } & & MCF7 \\
\hline 1 & ED (1:3) & 74.65 \\
\hline
\end{tabular}

1:1.5, 1:2, 1:3, 1.5:1 and 2:1) were prepared with each polymer by varying the concentrations of drug and polymer.

Out of six formulations of Eudragit ${ }^{\circledR}$ S100, F4 formulation was found to be the best formulation with drug content of $93.1 \%$, entrapment efficiency of $82.5 \%$, loading capacity of $25.04 \%$, mean particle diameter of $704.3 \mathrm{~nm}$, zeta potential value of $-21.3 \mathrm{mV}$. Invitro drug release data showed $89.8 \%$ of drug release controlled up to $12 \mathrm{~h}$.

Out of six formulations of ethyl cellulose, F4 formulation was found to be the best formulation with 


\section{Sample Details}

Sample Name: ED 1:3_Methotrexate 1

SOP Name: Zeta Potential DIP CELL_sop

General Notes:

File Name: college samples.dts

Record Number: 27

Dispersant Name: Water

Dispersant Rl: 1.330

Dispersant Dielectric Constant: 78.5

Viscosity (cP): 0.8872

Date and Time: Thursday, September 06, 2018 5:15:42 PM

\begin{tabular}{|c|c|c|c|c|c|c|}
\hline \multicolumn{7}{|l|}{ System } \\
\hline \multirow{2}{*}{$\begin{array}{l}\text { Temperature }\left({ }^{\circ} \mathrm{C}\right): \\
\text { Count Rate (kcps): }\end{array}$} & 25.0 & \multicolumn{3}{|r|}{ Zeta Runs: } & 30 & \\
\hline & 297.7 & Me: & asurement $\mathrm{Po}$ & sition $(\mathbf{m m})$ : & 4.50 & \\
\hline Cell Description: & Zeta dip cell & & & Attenuator: & 7 & \\
\hline \multicolumn{7}{|l|}{ Results } \\
\hline & & \multicolumn{2}{|r|}{ Mean $(m V)$} & \multicolumn{2}{|c|}{ Area (\%) } & St Dev (mV) \\
\hline Zeta Potential $(\mathrm{mV})$ : & -21.3 & Peak 1: & -21.3 & \multicolumn{2}{|l|}{100.0} & 6.63 \\
\hline Zeta Deviation (mV): & 6.63 & Peak 2: & 0.00 & \multicolumn{2}{|l|}{0.0} & 0.00 \\
\hline Conductivity $(\mathrm{ms} / \mathrm{cm})$ : & 0.0352 & Peak 3: & 0.00 & \multicolumn{2}{|l|}{0.0} & 0.00 \\
\hline
\end{tabular}
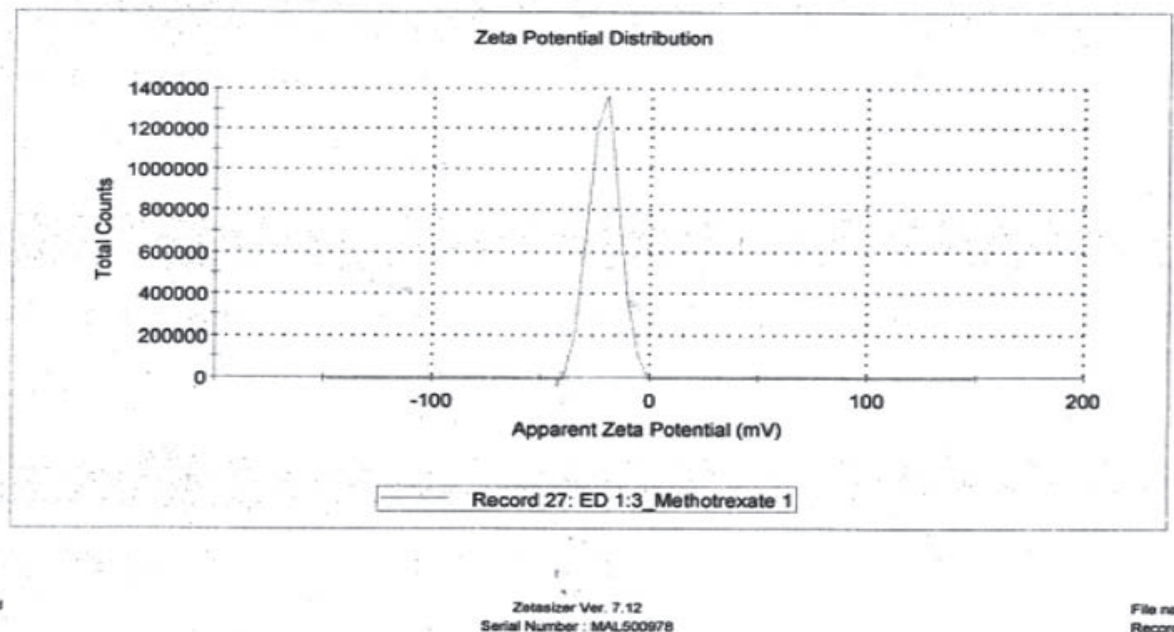

Fig. 10 Zeta potential analysis of F4 formulation.

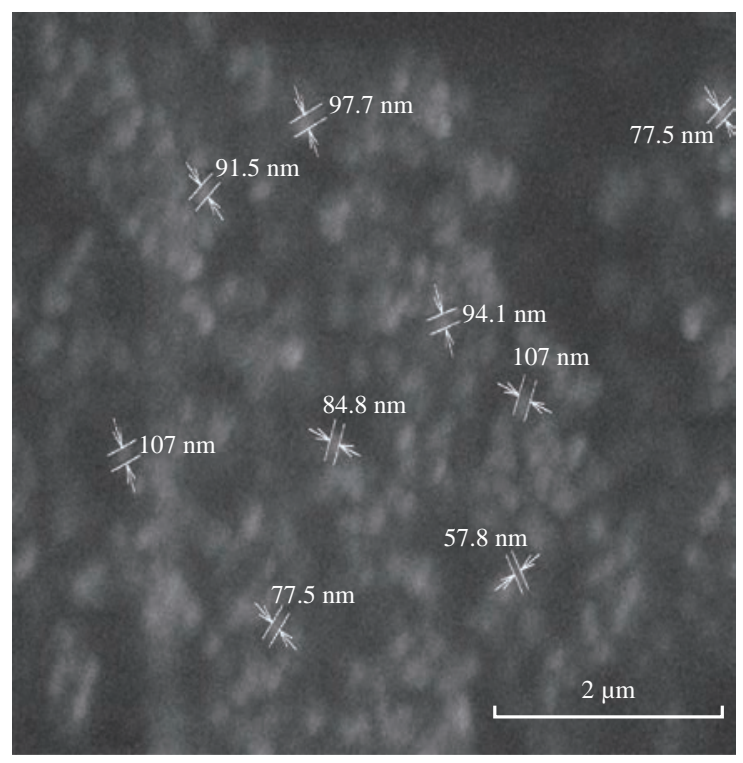

Fig. 11 SEM of F4 formulation. drug content of $75 \%$, entrapment efficiency of $79.3 \%$, loading capacity of $18.1 \%$, mean particle diameter of $622.6 \mathrm{~nm}$, zeta potential value of $-23.3 \mathrm{mV}$. Invitro drug release data showed $90 \%$ of drug release controlled up to $12 \mathrm{~h}$. In-vitro drug release studies and its data analysis have proven that all the formulations showed a sustained release that followed zero order and fickian type of diffusion pattern.

Based on the characterization and evaluation parameters, F4 (1:3) formulation using Eudragit ${ }^{\circledR}$ S100 as a polymer was found to be the best formulation by nanoprecipitation technique. This formulation was considered for determining anticancer activity by MTT assay in MCF-7 breast cancer cell line. From the results it was found that the formulation exhibited anticancer activity at an $\mathrm{IC}_{50}$ value of $74.65 \mu \mathrm{g}$. 


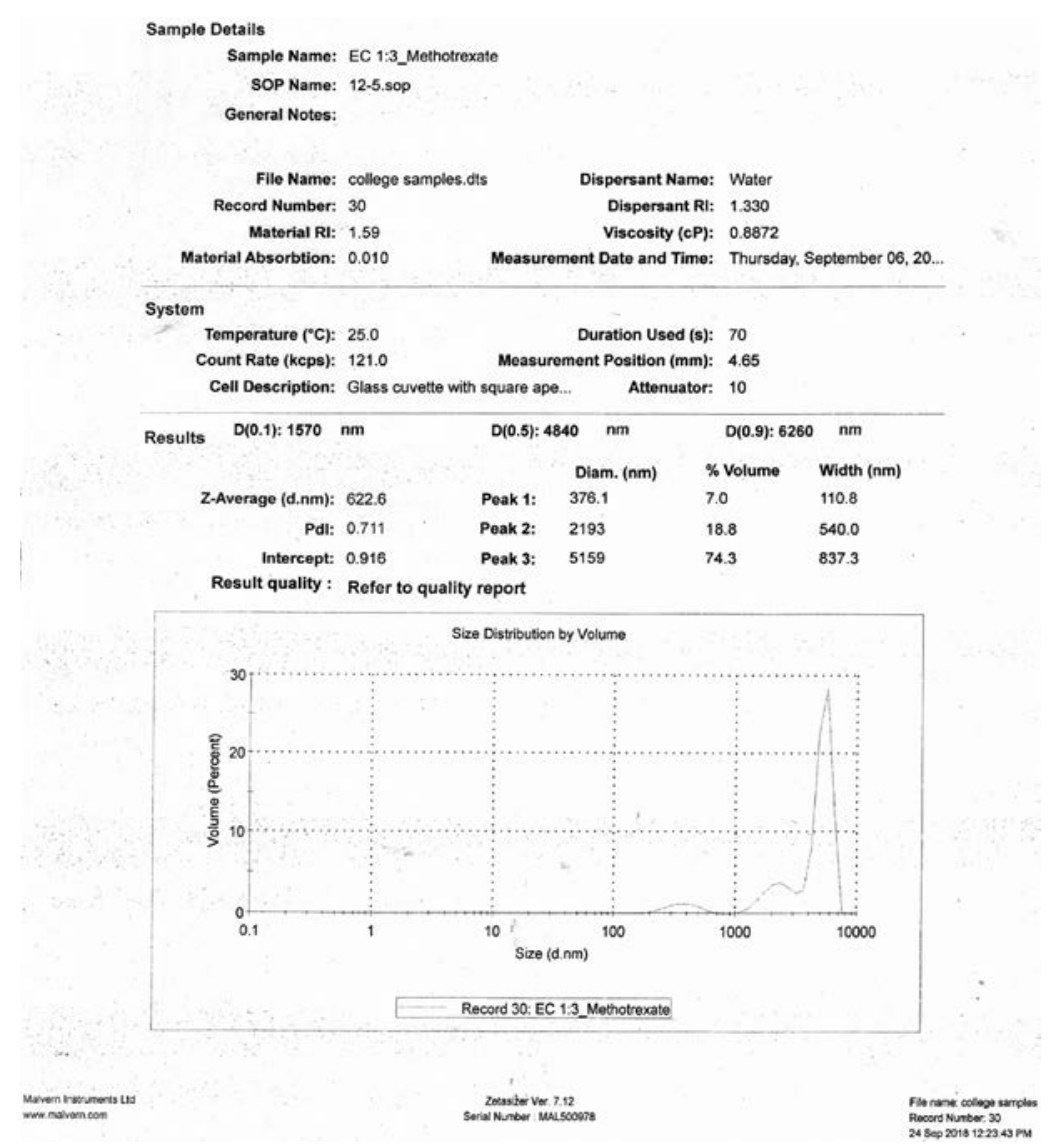

Fig. 12 Particle size analysis of F4 formulation.

Sample Details

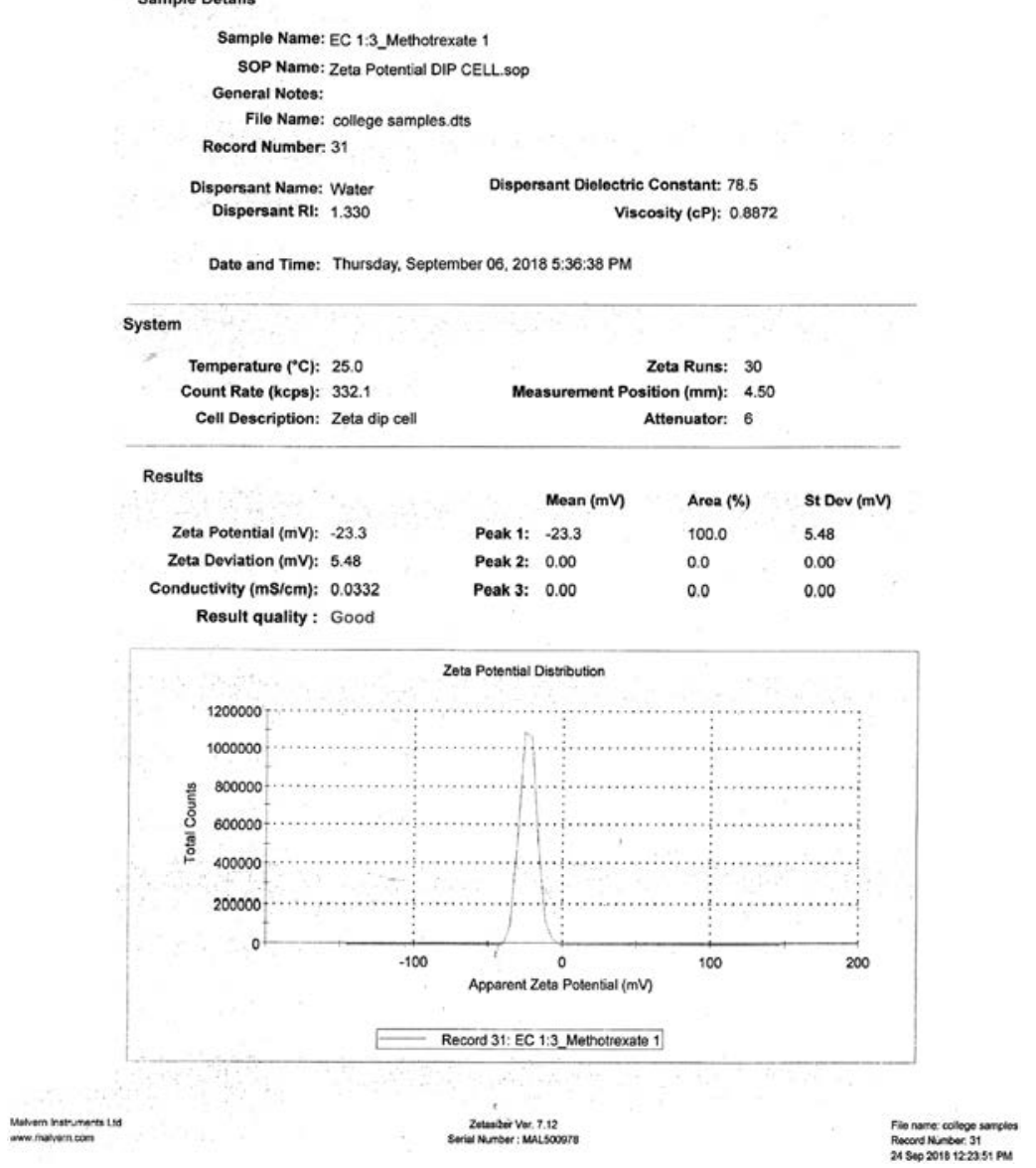

Fig. 13 Zeta potential analysis of F4 formulation. 


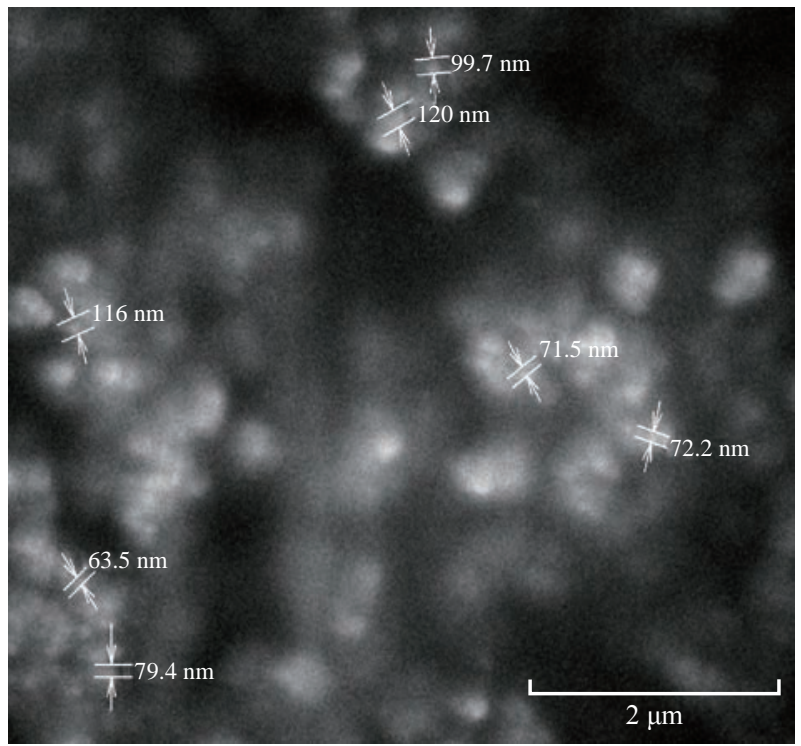

Fig. 14 SEM of methotrexate-ethyl cellulose F4 formulation.

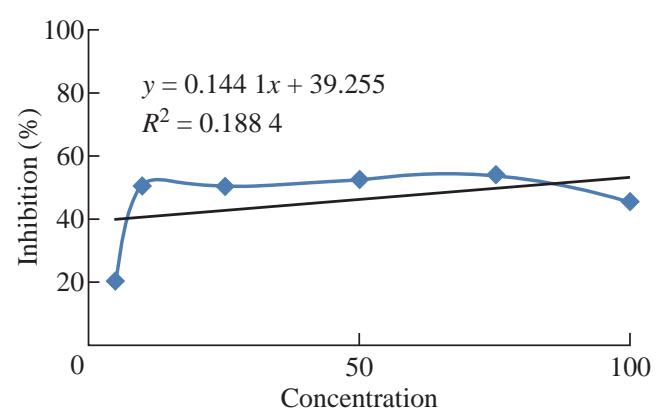

Fig. 15 Cytotoxicity effect of methotrexate-EC (1:3) on the growth of MCF-7 cell line.

\section{Conclusions}

Both polymers were compared for the characterization and evaluation parameters. By comparison, Eudragit ${ }^{\circledR}$ S100 was found to be a better polymer over ethyl cellulose for the preparation of methotrexate nanoparticles because of its smaller mean particle diameter $(704.3 \mathrm{~nm})$, higher stability $(-21.3)$, greater entrapment efficiency ( $82.5 \%)$, and anti-cancer activity at an $\mathrm{IC}_{50}$ value of $74.65 \mu \mathrm{g}$.

\section{Acknowledgements}

The authors would like to thank RBVRR Women's College of Pharmacy, Principal Dr. M. Sumakanth for providing us funds for the work. The authors would like to acknowledge Mrs. K. Sumalatha and Mrs. D. Suvarna for providing us technical assistance.

\section{References}

[1] N. Jawahar, D.N. Venkatesh, R.S. Kumar, et al.,
Development and charecterization of PLGA-nanoparticles containing carvedilol. J. Pharm. Sci. \& Res., 2009, 1(3): 123-128.

[2] N. Jawahar, T. Eagathappanath, N. Venkatesh, et al., Preparation and characterisation of PLGA-nanoparticles containing an antihypertensive agent. International Journal of PharmTech Research, 2009, 1(2): 390-393.

[3] S.K. Yadav, S. Mishra, and B. Mishra, Eudragit-based nanosuspension of poorly water-soluble drug: Formulation and in vitro-in vivo evaluation. AAPS PharmSciTech, 2012, 13(4): 1031-1044.

[4] B. Laxmi, N. Ghillare, Development of biocompatible nanoparticles for sustained topical delivery of rutin. International Journal of Pharmaceutical \& Biological Archives, 2012, 3(2): 326-332.

[5] S. Sahu, S. Saraf, and C.D. Kaur. Biocompatible nanoparticles for sustained topical delivery of anticancer phytoconstituent quercetin. Pak J Biol Sci, 16(13): 601.

[6] M. Morgen, C. Bloom, and R. Beyerinck, Polymeric nanoparticles for increased oral bioavailability and rapid absorption using celecoxib as model of a low-solubility, high permeability drug. Pharm Res, 2012, 29(2): 427-440.

[7] R. Choudhary, L. Goswami, and P. Kothiyal, Preparation of nanoparticles loaded nasal gel of mirtazapine for the treatment of depression. Journal of Advanced Pharmaceutical Sciences, 2013; 3(2):511-520.

[8] M.Bharathi, S. Chandra, R.L. Eswari, et al., Preparation and in vitro \& in vivo characterization of valsartan loaded eudragit nanoparticles. Der Pharmacia Sinica, 2012, 5: 516-525.

[9] J. Tang, N. Xu, H. Ji, et al., Eudragit nanoparticles containing genistein: formulation, development and bioavailability assessment. Int J Nanomedcine, 2011, 6: 2429-2435.

[10] A. Alshamsan, Nanoprecipitation is more efficient than emulsion solvent evaporation method to encapsulate cucurbitacin I in PLGA nanoparticles. Saudi Pharmaceutical Journal, 2013.

[11] A.A.Kharia, Formulation and evaluation of polymeric nanoparticles of an anti-viral drug for gastroretention. International Journal of Pharmaceutical Sciences and Nanotechnology, 2012, 4(4): 1557-1562.

[12] N. Paresh. L.J. Patel, Development and testing of novel temoxifen citrate loaded chitosan Nanoparticles Using Ionic gelation method. Der Pharmacia Sinica, 2(4), 2011: 17-25.

[13] S.P. Kaur, R. Rao, and A. Hussain, Preparation and characterization of rivastigmine loaded chitosan nanoparticles. J. Pharm. Sci. \& Res, 2011, 3(5): 12271232.

[14] R. Thagele, A. Mishra, and A.K. Pathak, Formulation and characterization of clarithromycin based nanoparticulate drug delivery system. International Journal of Pharmacy and Life Sciences, 2011, 2(1): 510-515.

[15] M. Rafeeq. Development and characterization of chitosan nanoparticles loaded with isoniazid for the treatment of Tuberculosis. Research Journal of Pharmaceutical, Biological and Chemical Sciences, 2010, 1(4): 383-390.

[16] J.A.J. Nesalin. G. Kuppusamy, and K.M. Doddi, Formulation and evaluation of nanoparticles containing Flutamide. Int. J. ChemTech Res., 2009, 1(4): 1331-1334.

[17] F. Sarei, N.M. Dounighi, H. Zolfagharian, et al., Alginate Nanoparticles as a promising adjuvant and vaccine delivery system. Indian J Pharm Sci, 2013, 75: 442-449.

[18] Drug Bank: Methotrexate (DB00563).

[19] A. Sonje, A. Chandra, Comprehensive review on Eudragit polymer. International Research Journal of Pharmacy, 2013, 4(5): 71-74.

[20] Eudragit@ functional polymers for oral solid dosage forms. <http://eudragit.evonik.com/product/eudragit/ 
Documents/evonik-specificationeudragit-l-100-s-100. pdf $>$.

[21] Eudragit@ acrylic polymers for solid oral dosage forms. $<$ http://www.rofarma.com/allegati/97.pdf>.

[22] R.C. Rowe, P.J. Sjeskey, and M.E. Quinn, Hand book of pharmaceutical excipients. Pharmaceutical Press and American Pharmacists Association, 2009: 262-266.

[23] S.W. Jacob, M. Bischel, and R.J. Herschler, Dimethyl sulfoxide (DMSO): A new concept in pharmacotherapy. Current Therap. Res., 1964, 6: 134-135.

[24] D.C. Pope, W.T. Oliver, Dimethyl sulphoxide. Can. J. Comp. Med. Vet. Sci., 1966, 20: 3-7.

[25] Acetone monograph 65. The Merck Index, $15^{\text {th }}$ ed. Royal Society of Chemistry, 2013: 13.

[26] R.C. Rowe, P.J. Sjeskey, and M.E. Quinn, Handbook of pharmaceutical excipients. Pharmaceutical Press and American Pharmacists Association, 2012: 620-624.
[27] J.M. Barichello, M. Morishita, K. Takayama, et al., Encapsulation of hydrophilic and lipophilic drugs in PLGA nanoparticles by the nanoprecipitation method. Drug Development and Industrial Pharmacy, 1999, 25(4): 471-476.

[28] S. Schubert, J.T. Delaney, and U.S. Schubert, Nanoprecipitation and nanoformulation of polymers: From history to powerful possibilities beyond poly(lactic acid). Soft Matter, 2011, 7: 1581-1588.

Copyright $₫$ Ayesha Siddiqua Gazi, Abbaraju Krishnasailaja. This is an open-access article distributed under the terms of the Creative Commons Attribution License, which permits unrestricted use, distribution, and reproduction in any medium, provided the original author and source are credited. 